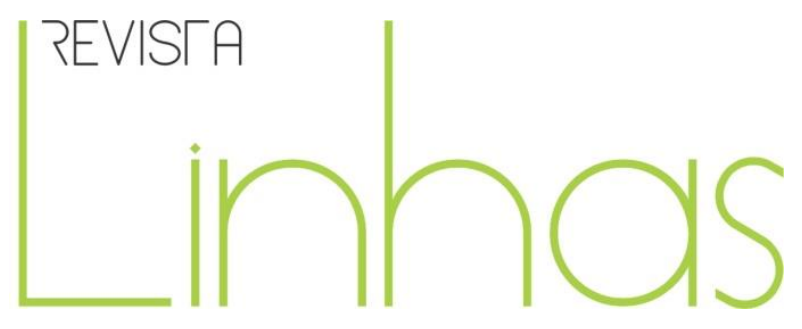

\title{
O professor universitário em processo de formação continuada: uma análise da docência no cotidiano da ação
}

\begin{abstract}
Resumo
O presente trabalho resulta de uma pesquisa de caráter qualitativo, realizada por meio de entrevistas, utilizando questões semiestruturadas com dez professores-formadores, atuantes em um curso de licenciatura. No estudo, foram abordadas questões que versam sobre a atuação docente e as situações que remetem a frustrações e à idealização desse processo. A pesquisa visou à compreensão de como os saberes docentes podem amparar a construção de novos olhares para "o fazer" do professor-formador no cotidiano de sua ação. A análise dos dados se efetivou com base nos procedimentos da Análise Textual Discursiva. Como resultado, os entrevistados relacionam as situações de frustração e a idealização na atuação pedagógica com questões relativas ao planejamento, ao domínio de conteúdo e aos aspectos das relações interpessoais. Entende-se que algumas dessas situações podem ser superadas/potencializadas em processos de interlocução entre os professores em espaços/tempos intra-institucionais, em que as reflexões coletivas se fazem permanentes e constitutivas de uma forma de pensar a formação continuada.
\end{abstract}

Palavras-chave: Professores Universitários. Formação. Ensino Superior.

\author{
Ademar Antonio Lauxen \\ Universidade Federal do Rio \\ Grande do Sul - UFRGS - Porto \\ Alegre/RS - Brasil \\ adelauxen@upf.br \\ José Claudio Del Pino \\ Universidade Federal do Rio \\ Grande do Sul - UFRGS - Porto \\ Alegre/RS - Brasil \\ delpinojc@yahoo.com.br
}

\footnotetext{
Para citar este artigo:

LAUXEN, Ademar Antonio; DEL PINO, José Claudio. O professor universitário em processo de formação continuada: uma análise da docência no cotidiano da ação. Revista Linhas. Florianópolis, v. 19, n. 40, p. 394413, maio/ago. 2018.
} 


\title{
The university professor in the process of continuous training: a teaching analysis on the action routine
}

\begin{abstract}
This project is the result of a qualitative research, performed by means of interviews, using semi structured questions, with ten teacher-trainers, active in a teaching degree course. Matters related to the teaching practice and situations that remit to frustrations and the idealization of this process, were addressed in this study. The research aimed towards the comprehension of how the teaching knowledge can support the construction of new points of view regarding the "doing" of the teacher-trainer in the routine of his action. This analysis took place based on procedures of a discursive textual analysis. As a result, the respondents relate situations of frustration and the idealization of pedagogical practice with matters related to planning, subject mastery and aspects of interpersonal relations. It is understood that some of these situations may be overcome/potentiated in processes of interlocution among the teachers in intrainstitutional time/spaces, in which collective reflections are permanent and constitutive in a way of thinking the continuous training.
\end{abstract}

Keywords: University Professors. Formation. Higher Education. 


\section{Introdução}

A docência, especialmente no ensino superior, tem passado por um processo de autocrítica, em que se busca repensar a atividade docente, tentando perceber valores e significados até então desconsiderados. Outrora, a função docente assentava-se “[...] em ensinar um corpo de conhecimentos estabelecidos e legitimados pela ciência e pela cultura, especialmente pelo valor intrínseco que eles representavam" (CUNHA, 2007, p. 14). Nessa perspectiva, segundo Cunha (2007), constituía-se como elemento fundante a lógica organizacional do conteúdo a ser ensinado, não havendo maiores preocupações com aqueles que eram sujeitos desse processo e, tampouco, com o contexto em que esse deveria acontecer. Essa lógica passa a ser questionada, apontando que o "[...] trabalho docente deve privilegiar não apenas o processo de ensino, mas o processo de ensinoaprendizagem, em que a ênfase esteja presente na aprendizagem dos alunos e não na transmissão de conhecimentos por parte dos professores" (MASETTO, 1998, p. 12).

A busca por alternativas para a ruptura com um processo de docência que se distancie das atuais exigências e que possa contribuir para avanços tem sido pauta de debates, estudos e pesquisas. Fruto de processos de reflexões sistemáticas, aceita-se que a docência no ensino superior não pode mais ser pensada sem que a ela esteja atrelada à constituição de saberes específicos que constituem essa ação, em que quem sabe, ensina, se souber ensinar.

Aceita-se, ainda, que à medida que o professor se torna capaz de identificar saberes concernentes e específicos do "ser educador" (TARDIF; LESSARD; LAHAYE, 1991), e, ao mesmo tempo, estabelece processos de reflexão sobre a complexidade do trabalho docente, amplia-se a possibilidade para que esse proponha melhores ambientes de aprendizagens para os seus alunos. Nessa perspectiva, ele se torna mais autônomo para propor a metodologia da sua aula, sendo capaz de tomar decisões de forma consciente, estabelecendo uma dinâmica coerente, que favorece a construção do conhecimento. Para consolidar essa dimensão, Schön (1995) aponta a importância da reflexão na, sobre e após a ação. Lauxen (2002) caracteriza a importância de perceber que esse processo de reflexão não deve se constituir como um exercício meramente introspectivo, mas ser algo que venha a ser feito no coletivo dos educadores, permitindo a construção de saberes advindos de uma prática refletida. Cunha (2007, p. 14) sinaliza que "[...] o 
exercício da docência nunca é estático e permanente: é sempre processo" e, sendo assim, requer a constante reflexão sobre o que esse processo exige e o que dele decorre, desenvolvendo a sensibilidade para olhar-se criticamente e poder avançar.

Acredita-se que, com base na reflexão, é possível surgirem processos de (re)significação da prática, ampliando a compreensão e a atuação do docente no complexo ato de ensinar. A docência não se faz somente no momento da sala de aula, ela constitui-se de ações que precedem esse momento; outras que ocorrem nesse espaço, e ainda, as que são posteriores. Todos esses momentos requerem a profunda reflexão do docente, rompendo com visões simplistas da docência, que, em muitos espaços de formação, ainda se apresentam como hegemônicas.

Entende-se que espaços/tempos intra-institucionais são importantes para promover novos estágios de compreensão aos sujeitos-atores do processo educativo. Assim, propõe-se a investigação de quanto um grupo específico de professores e professoras de uma instituição de ensino superior privado do interior do Rio Grande do Sul tem ampliado seus saberes docentes a partir de um espaço/tempo institucional existente, denominado Núcleo de Educação Química (NEQ), e, ainda, o quanto isso tem repercutido em mudanças no fazer pedagógico de cada um.

A pesquisa situa-se como possibilidade de estudo, discussão, investigação e reflexão com um grupo de professores-formadores, no sentido de viabilizar um olhar sobre o fazer pedagógico de cada um. Talvez, a primeira impressão que se possa ter é de que a pesquisa visou recuperar situações já cristalizadas, ou que serviu simplesmente para conhecer o que os professores e as professoras fazem para, então, exercer um controle ou modificar a sua prática. No entanto, um dos focos da pesquisa foi o de "[...] tornar os professores e professoras como pesquisadores e pesquisadoras e não como participantes de uma pesquisa cujo controle está fora do seu domínio" (GERALDI et al., 2011, p. 254). Além disso, também se buscou perceber como espaços/tempos institucionalizados viabilizam alternativas possíveis na direção de uma formação continuada e permanente para professores-formadores, entre seus pares, e, igualmente, esclarecer de que forma isso implica em melhorias na formação do futuro educador da educação básica. 
A pesquisa, de caráter qualitativo, ainda, se insere no âmbito da compreensão de como os saberes docentes podem amparar a construção de novos olhares para "o fazer" do professor-formador no cotidiano da sua ação. Essa ação é carregada de saberes derivados da sua experiência, as quais envolvem diversas variáveis e dizem respeito a cada educador, conforme Tardif (2014). Revelar esses saberes passa a ser relevante para o processo de avanço na melhoria da qualidade educativa, uma vez que junto com eles o educador vai estruturando a sua identidade profissional em um processo complexo, revelador de concepções e crenças. Nas palavras do autor:

[...] o saber dos professores é o saber deles e está relacionado com a pessoa e a identidade deles, com a sua experiência de vida e com a sua história profissional, com as suas relações com os alunos em sala de aula e com os outros atores escolares na escola. (TARDIF, 2014, p. 11)

Os professores-formadores participantes da pesquisa atuam em um curso de Licenciatura e, também, integram o Núcleo de Educação Química (NEQ), espaço/tempo intra-institucional em que eles se reúnem, quinzenalmente, para a troca de experiências na busca por uma reflexão permanente do fazer pedagógico deles próprios. Nesse espaço/tempo, são elaborados projetos, realizadas avaliações, elaborados e discutidos coletivamente materiais pedagógicos, como apostilas, livros e artigos, além de serem feitas análise de artigos e livros, dentre outras atividades.

\section{Procedimentos metodológicos e contexto da pesquisa}

A pesquisa, para dar conta da complexidade, teve uma abordagem qualitativa fenomenológica, deixando que os fenômenos se manifestassem sem impor direcionamentos (MORAES; GALIAZZI, 2011), reconhecendo a dimensão subjetiva da busca pelo conhecimento e as possibilidades de inferências que foram ocorrendo sobre os saberes do grupo de sujeitos participantes da pesquisa (BOGDAN; BIKLEN, 2010; LÜDKE; ANDRÉ, 2013). Ainda, se inseriu na modalidade de investigação-ação ou pesquisa em ação, pois ultrapassou as simples constatação e configuração de um problema, pois buscou estabelecer um sentido de horizontalidade no processo do conhecimento e ação entre pesquisador e realidade, pesquisador e pesquisado. 
Foi realizada uma entrevista, com questões semiestruturadas, com dez professores-formadores, atuantes em um curso de Licenciatura em Química e integrantes do NEQ, o qual é composto por professores que integram a área de Química de uma instituição de ensino superior privada. Todos foram convidados a participar da pesquisa, porém dois declinaram do convite. As entrevistas foram realizadas de forma individual, apenas entrevistador e entrevistado, gravadas em áudio, numa sala em que não houve interferência externa. Posteriormente, cada entrevista foi transcrita. Os sujeitos envolvidos na pesquisa preencheram e assinaram o Termo de Consentimento Livre Esclarecido (TCLE) em que foi explicitada a participação na atividade e garantida a preservação da identidade deles. Para identificá-los ao longo do texto em suas diferentes manifestações, atribuíram-se nomes fictícios, com base em nomes de personagem da História das Ciências da Natureza.

O grupo de dez pesquisados é constituído por educadores graduados em Química, havendo aqueles que atuam em disciplinas de conhecimentos específicos do curso e aqueles que ministram disciplinas de caráter prático-pedagógico. Quanto à participação no NEQ, o grupo é dinâmico na sua constituição, o que decorre do fato de os professores terem vínculo com a Área de Química e, nesse contexto, há professores horistas, com contrato temporário e outros que são professores efetivos. Dos dez entrevistados, há alguns com participação recente e outros que participam desde o início de sua constituição, em 2003.

Para este trabalho, a análise deu-se com base nos procedimentos da Análise Textual Discursiva (ATD), em função de seu caráter qualitativo, considerando os argumentos de Moraes e Galiazzi (2011, p. 13) sobre ATD, de modo que foi possível "[...] expressar novas compreensões alcançadas ao longo da análise" e descrevê-las e interpretá-las de forma a atingir um entendimento mais complexo dos discursos. A ATD pode ser entendida como um “[...] processo de desconstrução, seguido de construção, de um conjunto de materiais linguísticos e discursivos, produzindo-se, a partir disso novos entendimentos sobre os fenômenos e discursos investigados" (MORAES; GALIAZZI, 2011, p. 112).

Dessa forma, inicialmente, foi realizada a leitura das entrevistas de cada participante. A partir disso, iniciou-se a desconstrução desses enunciados e, na sequência, 
o processo de unitarização dos dados, em que se buscaram, nos fragmentos, as semelhanças, e, nesse movimento convergente, o sentido traçado foi de agrupar tais enunciados.

\section{Reflexões sobre a formação profissional: a docência como foco do debate}

Os educadores têm saberes, muitos deles trazidos ainda de antes da sua formação inicial. Tardif (2014) denomina os saberes docentes como: de formação profissional, das disciplinas, curriculares e experienciais. Cada saber inclui diversas particularidades, as quais unidas formam o modus do educador, determinando a sua práxis. Os saberes de formação profissional contemplam aqueles ditos "saberes pedagógicos", os quais são adquiridos ao longo da formação inicial e continuada do professor. Quanto aos saberes advindos da prática profissional, entende-se que devem ser revelados, especialmente para que se possa entender como esses se articulam no interior das instituições, compreendendo como os educadores os aplicam, os utilizam, os reelaboram e os produzem nas situações concretas e complexas da prática, constituindo-se em saberes da ação e não para a ação, conforme apontado por Tardif (2014). Nos cursos de graduação, nem todos os professores-formadores tiveram uma formação voltada para a docência. Sobre esse último aspecto, Maldaner (1999, p. 289-290) corrobora afirmando que:

O despreparo pedagógico dos professores universitários, também fruto de sua própria formação, afeta a formação em química de todos os profissionais que necessitam dessa área do conhecimento e afeta a todas aquelas pessoas que passam pelo ensino médio sem terem tido a oportunidade de uma formação mínima em química. Geralmente os professores universitários se comprometem pouco, muito aquém do necessário, com essa questão da formação dos professores e com a sua auto-formação pedagógica, deixando para um outro grupo, externo ao curso de química, a formação didático-pedagógica de seus alunos que desejam se licenciar e exercer o magistério.

Para minimizar parte dessa fragilidade na formação dos professores-formadores, as coordenações dos Cursos de Química Licenciatura e Bacharelado de uma universidade privada propuseram, em 2003, a criação do NEQ, visando à constituição de um espaço/tempo de discussão e elaboração coletiva, o qual implicasse uma determinada 
carga horária para que todos os professores da área de Química pudessem participar. Nesse espaço/tempo, os professores-formadores são desafiados e desafiam-se a refletir sobre percepções e concepções que os constituem, percebendo-se como sujeitos que produzem saberes da ciência e da cultura erudita, mas que precisam interpretar a prática que desenvolvem, especialmente no sentido de perceber "a possibilidade de aceitar que os conhecimentos científicos e técnicos necessários ao professor podem ser acrescidos de saberes da experiência e do campo da intuição [...]" (CUNHA, 2007, p. 14). Para isso, deve haver a responsabilidade dos docentes na problematização e significação dos conhecimentos sobre a sua prática, de modo a perceberem que "[...] o exercício da docência e o exercício de investigação são constituintes de um mesmo processo" (UBERTI; BELLO, 2013, p. 28).

Diante disso, torna-se relevante compreender como ocorre o processo de formação continuada desse grupo de professores-formadores integrantes do NEQ, em que se estabelece o diálogo entre os pares, desencadeando processos de inter-relações e produção de saberes, os quais, almeja-se, tornem-se saberes para a docência. Igualmente importante é buscar entender quanto esse processo contribui para que a constituição de educador se faça na perspectiva do sujeito reflexivo, tal como defendida por Schön (1995) e, ainda, esclarecer o quanto esse processo é importante, já que a grande maioria dos estudos que tratam de formação continuada em serviço estão voltados para os educadores da educação básica e poucos mencionam os professores da educação superior.

Dez professores-formadores que integram esse espaço/tempo de formação continuada e atuam no curso de Licenciatura em Química foram entrevistados para a presente pesquisa, sendo que, neste trabalho, o foco são as questões que seguem, as quais nortearam as entrevistas de forma que essas não fossem completamente estruturadas ou exclusivas, pois, quando necessário, foram feitas perguntas complementares que pudessem ajudar a obter novas informações ou esclarecimentos sobre as enunciações dos entrevistados. 
1) Quando você está desenvolvendo a sua aula, na interação com os estudantes, sempre ocorre uma infinidade de situações ricas em possibilidades, porém, outras que são frustrantes e limitantes.

a) Quais situações que você vivenciou em suas aulas que citaria como ricas em possibilidades para o desenvolvimento de um bom processo de aprendizagem? Por quê?

b) Quais situações ou fatores que destacaria como limitantes ou que acarretam frustração na ação docente? Por quê?

c) Descreva em linhas gerais qual proposta de trabalho que acredita ser a ideal, e que possibilitaria você desenvolver a sua melhor aula? Que característica teria a sua melhor aula?

2) Que característica teve a aula em que você saiu mais frustrada(o) ou considerou sua pior atuação pedagógica? Por quê?

Ao analisar as transcrições das entrevistas, é possível identificar que, para quatro dos entrevistados, a aula que gerou maior frustração está relacionada ao domínio do conteúdo, especialmente quando eles não se sentiam preparados para desenvolver a temática daquela aula. Para o professor Thomas “[...] foi bem frustrante, a palavra é essa mesma, frustrante, porque eu não conseguia desenvolver da maneira que achava que deveria ser desenvolvido aquilo. Tentar dar as explicações, [...] por mais que, às vezes o aluno não pergunte, mas você mesmo está olhando ali e não sabe, mas por que que é isso $[\ldots] "$.

Outros estudos (PEREIRA; NÖRNBERG, 2012; PACHANE, 2012; CÂNDIDO et al., 2014) indicam que os estudantes reconhecem como importante o domínio do conteúdo pelo educador, sendo uma das principais características que eles vinculam como relevante ao reconhecerem um bom professor. A professora Irene, que também apontou como frustrante uma aula em que se sentiu despreparada em termos de domínio dos conhecimentos da disciplina, afirmou: “[...] foi uma aula que eu não me sentia preparada o suficiente para o que eu estava discutindo. Eu percebia que à medida que eu tentava dar aquela aula, ela se tornava cada vez mais 'eu falando: eu e o quadro'. Os estudantes cada vez mais distantes do que eu estava dizendo [...]”. A primeira percepção que se tem 
é de que a ação docente está muito centrada na transmissão do conhecimento, havendo uma preocupação dos professores com o ensino, não com o ensino-aprendizagem.

Precisa-se pensar que o professor, outrora detentor absoluto do conhecimento e das fontes de consulta, passou, nos últimos tempos, a desempenhar um novo papel, pois o saber publicado não mais lhe pertence com prerrogativas de privilégio. $\mathrm{O}$ acesso ao conhecimento registrado pode ser agora obtido em segundos, e de várias fontes, e portanto, não poderá ser usado como premissa de autoridade (LAUXEN et al., 2016).

Aceita-se, nessa nova condição, que o processo formal educativo assuma uma postura dialógica. Sendo assim, muitas vezes, nesse processo em que o professor ainda se percebe como alguém que precisa dominar todas as informações, pode ser tomado de frustrações, pois os estudantes estão imersos num contexto em que tais situações se fazem presentes. É necessário pensar como problematizar esse conjunto de informações e, nesse processo dialógico de saberes, construir/reconstruir novos conhecimentos. É fundamental pensar na direção do que aponta Schulman (1986), ao afirmar que o conhecimento pedagógico do conteúdo é que difere o professor dos demais profissionais, mas, ao mesmo tempo, também não garante a eficácia/eficiência do processo de ensino e sua efetiva aprendizagem por parte do estudante.

Hoje é muito mais difícil ser professora e professor. Há um tempo, exercíamos nossa autoridade pelo quanto éramos competentes naquilo que sabíamos. Agora, somos superados no que nos distinguia pelos recursos tecnológicos que são informadores mais capazes. As exigências são outras. Temos que ser cada vez mais formadores. (CHASSOT, 2003, p. 56)

A racionalidade prática avança para essa reflexão, em que as ações são redimensionadas e os conhecimentos tácitos de ser e fazer docente são problematizados, permitindo esclarecimentos e o desenvolvimento de educadores como profissionais mais comprometidos com o processo de ensino-aprendizagem, no qual o conhecimento (produção e difusão) ganha nova definição. Segundo Rosa e Schnetzler (2003, p. 28), "ao se pensar em programas de formação continuada sob o prisma da racionalidade prática, é necessário então superar o hiato entre teoria e prática para fundamentar ações 
pedagógicas produzidas a partir de saberes tácitos dos professores”. E muitos desses saberes tácitos passam pela ideia de que basta o domínio do conteúdo para garantir ao professor o desenvolvimento de uma boa aula. Entende-se que o professor do ensino superior é um profissional e, como tal, precisa de formação e não apenas de preparação para o exercício da docência. O domínio do conhecimento específico de sua área é fundamental, porém o professor universitário necessita de uma profunda competência pedagógica, especialmente aqueles que são professores-formadores de futuros docentes da educação básica.

Romanowski (2012, p. 54) afirma que "Os saberes docentes compõem-se por saberes experiências, saberes pedagógicos e específicos; são saberes das lutas cotidianas" e aponta que "Os saberes pedagógicos são aqueles que se referem aos conhecimentos da didática, da psicologia da educação, da sociologia da educação e das demais ciências educacionais" (ROMANOWSKI, 2012, p. 55). Masetto (2012, p. 12) assevera para a necessidade de ruptura com uma compreensão em relação à ideia de que "quem sabe: automaticamente sabe ensinar". O autor indica que

\begin{abstract}
Recentemente, professores universitários começaram a se conscientizar de que seu papel de docente do ensino superior, como o exercício de qualquer profissão, exige capacitação própria e específica que não se restringe a ter um diploma de bacharel, de mestre ou doutor, ou apenas o exercício da profissão. Exige isso tudo e competência pedagógica, pois ele é um educador, alguém que tem a missão de colaborar eficientemente para que seus alunos aprendam. [...] Para se desempenhar bem esse papel, o professor necessita de uma formação pedagógica. (MASETTO, 2012, p. 15)
\end{abstract}

Irene, professora-formadora entrevistada, ao falar sobre a proposta ideal de aula sinaliza com uma perspectiva em que demonstra uma preocupação com a aprendizagem do aluno e sua participação no processo e, ao mesmo tempo, com a necessidade de uma competência pedagógica para desencadear essa ação. Reforça a necessidade do domínio do conhecimento, mas aponta para a importância de entrelaçá-los com aqueles que o estudante já tem. Irene afirmou: "minha melhor aula seria em que os alunos estivessem dispostos a participar, que eu tivesse conhecimento suficiente para conseguir fazer uma boa discussão com eles. Que eu conseguisse relacionar o conteúdo com as experiências 
dos estudantes". Da mesma forma, Pierre, outro professor-formador entrevistado, relatou, sobre essa mesma questão, que sua aula ideal seria “[...] com bastante diálogo, bastante participação [...] que o estudante conseguisse contextualizar".

Em geral, os entrevistados consideram relevante para uma aula ideal garantir a efetiva participação do estudante no processo, havendo por parte desse um maior comprometimento para com o aprender. Da mesma forma, os professores-formadores pesquisados consideram importante que os conteúdos sejam contextualizados e o conhecimento prévio do estudante seja considerado, havendo articulação entre ciência e tecnologia e, no processo de negociação de significados, seja possível chegar a consensos, entendendo que esses têm caráter de provisoriedade e estão sujeitos a contínuas reformulações. Desse modo, as ideias expressas pelos professores-formadores pesquisados apontam para os estudos de Ausebel (2003), sobre aprendizagem significativa, bem como o que é discutido por Hmelo-Silver e Barrows (2008) sobre a importância da interação entre os pares, apontamentos que contribuem para a discussão das diferentes temáticas, em que as concepções e os conhecimentos prévios dos próprios estudantes devem ser considerados para o processo de ensino e aprendizagem. Moreira e Sperling (2009) corroboram com essa compreensão na medida em que, também, apontam que os conhecimentos prévios são importantes para a construção do conhecimento e, devem ser considerados no processo de ensino-aprendizagem, uma vez que aprendemos a partir daquilo que já sabemos.

As ideias trazidas pelos professores de uma aula ideal não se distanciam daquilo que poderia ser o real, pois esses entendem como fundamental que o professor, como mediador do conhecimento para o estudante, valorize o saber desse sujeito com o qual ele interage no processo de construção de conhecimentos, tornando esses mais contextualizados e significativos.

Essa aproximação fica demonstrada nas respostas apresentadas pelos entrevistados sobre situações que vivenciaram nas quais houve ricas possibilidades de aprendizagem por parte dos estudantes. Algumas afirmações dos entrevistados sobre essa questão seguem abaixo: 
Irene: Penso que mais ricas foram aquelas em que os estudantes estavam interessados e participaram, porque a participação deles permite que as nossas discussões fiquem bem mais ricas, diferente quando eu vou para a sala de aula e os estudantes não participam [...] no momento em que os estudantes se envolvem e participam, eles trazem as experiências deles [...] cada um vai fazendo as suas colocações, ela se torna muito mais rica, muito mais ampla.

Max: Eu poderia citar algumas aulas de [...], principalmente porque os estudantes conseguem fazer um paralelo com a vivência deles [...], permitindo um diálogo entre o professor e o aluno, especialmente nesse processo de formação de professores [...] essa possibilidade de diálogo, a ser estabelecido, tentando aproximar com a realidade, com o contexto do aluno e possibilitando a participação deles.

Pierre: [...] quando propus discussão de um determinado assunto, e tive a participação dos alunos [...] eles partem da vivência deles, então eles vão falando a respeito daquilo [...] penso que é uma das formas mais ricas de trabalhar o conhecimento.

Como é possível perceber, o que os professores-formadores afirmam terem vivenciado como situações ricas em possibilidades para o desenvolvimento de um bom processo de aprendizagem aproxima-se daquilo que eles argumentam como sendo a sua proposta para uma aula ideal, em que ocorre uma preocupação com o ensinoaprendizagem, deslocando o foco da figura do professor para o processo. Nesse processo de ensino-aprendizagem, os conhecimentos são compartilhados, construídos, e elaborados por ambos, professor e aluno. O que se depreende das afirmações dos professores pesquisados é que, tanto naquilo que idealizam, quanto naquilo que procuram concretizar em suas aulas, há a busca por uma dinâmica "[...] centrada na relação permanente entre o professor e os alunos. [...] um processo em que o professor, ao realizar o ensino, produz com os alunos a aprendizagem. A atividade docente é interativa, precisa da participação dos discentes para concretizar-se" (ROMANOWSKI, 2012, p. 47).

Assim, uma dita boa prática pedagógica não se configura apenas na mobilização de conhecimentos e prescrições, mas também no interior de um imbricado sistema de regras e coerções, que está ligada à forma pela qual cada indivíduo torna-se sujeito aos saberes e poderes de seu tempo. (UBERTI; BELLO, 2013, p. 24) 
No que diz respeito ainda às frustrações, três educadores apontaram que essas se deram pelo viés do planejamento. A professora Dorothy afirma que a sua frustração está relacionada ao tempo e ao planejamento: “[...] quando eu não consigo dar conta do tempo daquele momento que eu planejei. E aí são 'n' motivos, ou a turma é diferente, ou eles têm um encaminhamento diferente daquilo que eu planejei, ou falta a base e eu preciso retomar [...]". Analisando a argumentação da professora Dorothy, pode-se pensar que, talvez, ela não esteja considerando no seu planejamento as características dos estudantes, ou do conjunto dos estudantes, e seus saberes. Mas a mesma professora Dorothy, quando indagada sobre a aula ideal, também remete à questão do planejamento como enfoque principal. Ela afirma: “[...] uma aula que seja satisfatória é aquela que eu tenho o objetivo claro, que eu sei exatamente o que eu quero com aquela aula [...] eu consiga perceber que atendi aqueles objetivos, aquele planejamento que eu fiz". Entende-se que o planejamento não deve ser pensando como algo pronto, imutável, definitivo e que não tenha margem para a flexibilidade. Planejamento é uma aproximação entre as estruturas que se apresentam e aquilo que o professor idealiza e, à medida que se desenvolve o processo, sucessivos replanejamentos ocorrem, tornando-se cada vez mais apropriado ao contexto com o qual o professor trabalha. Assim, o professor passa de uma situação "real”, na direção daquilo que tem como "ideal”, e se concretiza dentro das possibilidades e circunstâncias. "É possível fazer do planejamento um rico momento de trocas e melhor entendimento da ação de ensinar e de aprender" (ANASTASIOU, 2004, p. 59).

Marie, também apresentou sua frustração quando precisou redirecionar o seu planejamento: “[...] eu já tinha feito uma coisa que não precisava, claro revisar e coisas, e eles não enxergaram aquilo. Então, eu falei, espera aí! Fica frustrante, o que eles querem efetivamente, porque eu não gosto quando eles fazem essas coisas, uma exigência que não tem fundamento [...]". Sabe-se que o planejamento se configura como aliado para que o processo educativo se desenvolva adequadamente na ação. Esse se caracteriza como atividade consciente de previsão do tempo e do espaço de trabalho do professor, orientando a sua ação educativa de forma eficaz, do que decorrem processos reflexivos. Como afirma Schön (2007, p. 16), “[...] os problemas da prática do mundo real não se apresentam aos profissionais com estruturas bem-delineadas. Na verdade, eles tendem a 
não se apresentar como problemas, mas na forma de estruturas caóticas e indeterminadas", o que ocorre, também, na ação docente, que, portanto, requer um planejamento que permita flexibilidade e readequação. O profissional deverá ser capaz de selecionar, organizar, sistematizar, prever, decidir, avaliar a situação e estabelecer uma ação coerente com base nesse redirecionamento, garantindo a eficiência e a eficácia, tendo o planejamento como ato político-pedagógico que revela intenções e intencionalidades.

Outros três destacaram que a frustração se deu motivada pela relação professoraluno, pela dificuldade de se estabelecer um processo mais claro de inter-relação entre educador e educandos. Dois entrevistados fizeram menção a suas experiências na educação básica. O professor Max apontou que sua frustrante experiência se deu no ensino fundamental, quando ainda no começo de carreira, por entender que tinha dificuldade de estabelecer um maior "domínio da turma”, não obtinha bons resultados na sua atuação pedagógica: "[...] foram situações bem complicadas no sentido de tentar conseguir o domínio da turma, uma fase rebelde dos alunos, naquela mudança onde eles tinham mais disciplinas no currículo". Huberman (2000), ao discutir O Ciclo de Vida Profissional dos Professores, aponta que o contato inicial com a carreira docente se caracteriza pelo estágio da "sobrevivência" e de "descoberta". O aspecto da "sobrevivência" se configura pelo "choque do real”, em que as demandas se apresentam revestidas de complexidade, que, muitas vezes, sinalizam o distanciamento que há entre os ideais e as realidades que o professor vivencia no contexto da sala de aula. Dentre essas demandas encontram-se: “[...] dificuldades com alunos que criam problemas [...]” (HUBERMAN, 2000, p. 39) e, como o autor afirma, dependendo de como esses dois perfis se combinam nesse processo inicial de carreira, poderá o educador ser levado a desenvolver um perfil de frustação. 


\section{Considerações finais}

Entende-se que a trajetória profissional de cada docente não é linear. Ela é feita de rupturas e continuidades, alegrias e frustrações, desalentos e motivações, que vão constituindo a sua identidade profissional. "A identidade é um lugar de lutas e de conflitos, é um espaço de construção de maneiras de ser e de estar na profissão" (NÓVOA, 2000, p. 16). Muitas vezes, a idealização e a frustração convivem no contexto da vida prática. Os avanços que possam ajudar o educador a melhorar a sua condição talvez estejam relacionados à constituição de coletivos de educadores em espaços/tempos intra-institucionais em que esses encontrem, em seus pares, os interlocutores para construir novos saberes, ampliar a compreensão de seus limites, superar concepções simplistas de práticas docentes, ampliando sentidos e significados, qualificando a ação.

O professor que se sente frustrado na sua ação docente, se apenas desenvolver um processo reflexivo individual, talvez não encontre saídas para suas demandas, porém, na medida em que estabelecer interlocução de saberes com seus pares, dialogar e refletir em espaços/tempos intra-institucionais, poderá avançar e, muitas vezes, não se sentir desestimulado e, como tantos, desistir da profissão ou rotinizar a sua prática. Esses espaços/tempos devem oportunizar que o professor construa processos que se aproximem das suas idealizações, em que reflete sobre o "real”, problematiza o "ideal” e concretiza o "possível”. Para que isso se concretize é necessário constituir

[...] espaço para a introdução ao pensar pedagógico, à reflexão sistemática da ação já em exercício em relação ao quadro teórico-prático da didática, possibilitando aos docentes um maior entrelaçamento com os próprios saberes, uma nova organização dos específicos da área, propositadamente transformados em saber escolar, uma revisão dos saberes da experiência e uma apresentação ou reapresentação dos pedagógicos. (ANASTASIOU, 2004, p. 63)

A formação dos futuros educadores da educação básica se encontra sob a responsabilidade das instituições de ensino superior, se constituindo numa tarefa difícil. Muitos professores-formadores foram formados com base numa racionalidade técnica, a qual tinha como princípios a formação de um professor "apto" a aplicar técnicas, 
metodologias e expor teorias prontas e desprovidas de reflexões e questionamentos, sem a valorização dos saberes advindos da prática. Assim, a realidade escolar era analisada com base em padrões pré-definidos, em que as discussões se davam sem se considerar os contextos específicos. Há, ainda, professores atuando em cursos de licenciatura sem formação pedagógica, e, portanto, a docência se faz pela formação ambiental/tácita. Partindo da premissa de que a prática docente constitui atividade complexa e que muitos dos professores que atuam nos cursos de licenciatura não compreendem essa complexidade, se esses professores não estabelecerem um processo de reflexão capaz de romper com a formação ambiental e tácita que constitui sua visão do ser educador, marcada por uma percepção simplista e reducionista do ser e fazer docente, provavelmente, formarão educadores nessa mesma perspectiva. E o ciclo continuará a se repetir.

Assim, habilitar o professor-formador a perceber a sua prática como espaço de pesquisa de forma permanente e desenvolver sua autonomia para torná-lo um sujeito reflexivo, não apenas em momentos individuais, mas também, em processos coletivos, em que haja a possibilidade de construção de saberes advindos de uma prática refletida poderá ser uma das formas para romper com o ciclo de formação de professores que não tencionam a formação tácita. Então, aceita-se como importante para produzir avanços, o fato de possibilitar em processos, inicial ou continuado, de formação, a ruptura com o modelo ancorado na racionalidade técnica, ainda presente em muitos espaços de formação docente, avançando para uma nova racionalidade, entendida como aquela que pensa a prática na formação dos professores, em que os saberes práticos e a experiência profissional se constituem em elementos fundantes para a formação dos profissionais da educação. Corroboram para a compreensão dessa ideia Uberti e Bello (2013, p. 21) ao afirmarem que

A prática, entendida como a realidade concreta e os saberes nela e por
ela produzidos, deve ser cotejada por referenciais teóricos outros, os
quais devem, necessariamente, retornar à prática em forma de ação.
Esse retorno da teoria à prática é o que complexifica e, portanto,
qualifica o conhecimento produzido.

Sendo assim, entende-se que espaços/tempos como o Núcleo de Educação Química (NEQ) podem ser onde isso venha a ocorrer, e, portanto, defende-se que esses 
espaços devam se constituir como algo institucionalizado, não apenas como uma possibilidade aos interessados no tema, mas como compromisso de todos os professores-formadores, de modo que deverá ocorrer o envolvimento com “[...] o conhecimento específico e o conhecimento pedagógico, num exercício interpessoal que requer respeito e humildade" (CUNHA, 2007, p. 19). Compartilha-se do entendimento de que o crescimento cognitivo, afetivo, intelectual e humano decorre de interações entre pessoas, num processo dialógico, remetendo a ações na direção de um caráter problematizador. Resta reafirmar a necessária ruptura com uma formação amparada na racionalidade instrumental, passando para um novo modo de ação, alicerçada numa racionalidade da prática, na dimensão crítico-reflexiva. Assim, a forte ênfase dada pelos professores pesquisados ao necessário domínio do conteúdo evidencia certa fragilidade na relação entre o ensinar e o aprender. Porém, no espaço/tempo que se constitui o NEQ, os professores-formadores integrantes da pesquisa têm a oportunidade de realizarem reflexões sistemáticas sobre suas práticas educativas e concepções pedagógicas, possibilitando avanços que permitam implementar aquilo que por ora idealizam.

\section{Referências}

ANASTASIOU, Lea das Graças Camargos. Da visão de ciência à organização curricular. In: ANASTASIOU, Lea das Graças Camargos. (Orgs.). Processos de ensinagem na universidade: pressupostos para as estratégias de trabalho em aula. Joinville: Univille, 2004. $3^{\text {a }}$ reimpressão. p. 39-65.

AUSUBEL, David Paul. Aquisição e Retenção de conhecimentos: uma perspectiva cognitiva. Lisboa: Plátano Edições Técnicas, 2003.

BOGDAN, Robert; BIKLEN, Sari Knopp. Investigação qualitativa em educação: uma introdução à teoria e aos métodos. Porto: Porto Editora, 2010.

CÂNDIDO, Cássia Marques; ASSIS, Monique Ribeiro de; FERREIRA, Nilda Teves; SOUZA, Marcos Aguiar de. A representação social do "bom professor" no ensino superior.

Psicologia \& Sociedade, Porto Alegre, v. 26, n. 2, 2014. p. 356-365,

CHASSOT, Attico. Educação ConSciência. Santa Cruz do Sul: Edunisc, 2003.

CUNHA, Maria Isabel da. O lugar da formação do professor universitário: a condição profissional em questão. In: CUNHA, Maria Isabel da. (Org.). Reflexões e práticas em pedagogia universitária. Campinas, SP: Papirus, 2007. p. 11-26. 
GERALDI, Corinta Maria Grisolia; MESSIAS, Maria da Glória Martins; GUERRA, Míriam Darlete Seade. Refletindo com Zeichner: um encontro orientado por preocupações políticas, teóricas e epistemológicas. In: GERALDI, Corinta Maria Grisolia; FIORANTINI, Dario; PAREIRA, Elisabete Monteiro de Aguiar (Org.). Cartografias do trabalho docente: professor(a) pesquisador(a). Campinas, SP: Mercado das Letras: Associação de Leitura do Brasil - ALB, 2011. p. 237-274. (Coleção Leituras do Brasil).

HMELO-SILVER, Cindy E.; BARROWS, Howard S. Facilitating collaborative knowledge building. Cogntion and Instruction, n. 26, p. 48-94, 2008.

HUBERMAN, Michael. O ciclo de vida profissional dos professores. In: NÓVOA, António. (Coord.). Vidas de professores. 2. ed. Porto: Porto Editora, 2000.

LAUXEN, Ademar Antonio. (Des)consideração das questões ambientais no ensino formal de ciências: o caso das escolas de Ibirubá. ljuí: Unijuí, 2002. 208 p.

LAUXEN, Ademar Antonio; MISTURA, Clovia Marozzin; PRADO, Edgardo Aquiles; ORTIZ, Janaína Chaves. A formação inicial em Química no contexto de uma universidade comunitária. In: ECHEVERRÍA, Agustina Rosa; ZANON, Lenir Basso (Orgs.). Formação superior em química no Brasil: práticas e fundamentos curriculares. 2. Ed. ljuí: Unijuí, 2016. p. 187-208.

LÜDKE, Menga; ANDRÉ, Marli Eliza Dalmazo Afonso de. Pesquisa em educação: abordagens qualitativas. $2^{\mathrm{a}}$ ed. Rio de Janeiro: EPU, 2013.

MALDANER, Otavio Aloisio. A pesquisa como perspectiva de formação continuada do professor de Química. Química nova. São Paulo: SBQ. V. 22, n. 2, mar./abr. 1999. p. 289292.

MASETTO, Marcos Tarciso. Professor universitário: um profissional da educação na atividade docente. In: MASETTO, Marcos Tarciso. (Org.). Docência na universidade. Campinas, SP: Papirus, 1998. p. 9-26.

MASETTO, Marcos Tarciso. Competência pedagógica do professor universitário. 2. Ed. São Paulo: Summus, 2012.

MORAES, Roque; GALIAZZI, Maria do Carmo. Análise textual discursiva. 2. ed. rev. Ijuí: Unijuí, 2011. 224 p.

MOREIRA, Marco Antonio; SPERLING, Carla Simone. Mapas conceptuales y aprendizaje significativo: ¿una correlación necesaria? Experiências em Ensino de Ciências, v. 4, n. 3, p. 91-100, 2009.

NÓVOA, António. Os professores: um "novo" objecto da investigação educacional?. NÓVOA, António. (Org.). Vidas de professores. 2. ed. Porto: Porto Editora, 2000. p. 14-30. 
PACHANE, Graziela Giusti. Quem é seu melhor professor universitário e por quê? Características do bom professor universitário sob o olhar de licenciandos. Educação. v. 37, n. 2. p. 307-320, maio/ago. 2012. Santa Maria-RS.

PEREIRA, Igor Daniel Martins; NÖRNBERG, Marta. Saberes Pedagógicos e a Prática do bom professor: o que expressam acadêmicos em estágio dos cursos de Pedagogia e Ciências Biológicas. In: ANPED SUL - SEMINÁRIO DE PESQUISA EM EDUCAÇÃO DA REGIÃO SUL, IX, Caxias do Sul-RS, 2012. [Anais...] 2012. Disponível em: http://www.ucs.br/etc/conferencias/index.php/anpedsul/9anpedsul/paper/viewFile/1173/5 66. Acesso em 06/04/15.

ROSA, Maria Inês de Freitas Petrucci dos Santos; SCHNETZLER, Roseli Pacheco. A investigação-ação na formação continuada de professores de ciências. Ciência e Educação. v. 9, n. 1, 2003. p. 27-39.

ROMANOWSKI, Joana Paulin. Formação e profissionalização docente. Curitiba: InterSaberes, 2012.

SCHÖN, Donald A. Formar professores como profissionais reflexivos. In: NÓVOA, António (Coord). Os professores e a sua formação. 2. Ed. Lisboa: Dom Quixote, 1995. p. 77-91.

SCHÖN, Donald A. Educando o profissional reflexivo: um novo design para o ensino e a aprendizagem. Porto Alegre: Artmed, 2007.

TARDIF, Maurice; LESSARD, Claude; LAHAYE, Louise. Os professores face ao saber: esboço de uma problemática do saber docente. Teoria \& Educação, Porto Alegre, n. 4, 1991.

TARDIF, Maurice. Saberes docentes e formação profissional. 17. Ed. Petrópolis, RJ: Vozes, 2014.

UBERTI, Luciane; BELLO, Samuel Edmundo Lopez. A docência-pesquisa em movimento no PIBID. In: UBERTI, Luciane; BELLO, Samuel Edmundo Lopez. (Orgs.). Iniciação à docência: articulações entre ensino e pesquisa. São Leopoldo: Oikos, 2013.

Universidade do Estado de Santa Catarina - UDESC Programa de Pós-Graduação em Educação - PPGE

Revista Linhas

Volume 19 - Número 40 - Ano 2018 revistalinhas@gmail.com 